\title{
SPATIAL DATABASE MODELING FOR SPELEOLOGICAL INVENTORY OF THE MOROCCAN ATLAS MOUNTAINS.
}

\author{
Fatima EL HAMMICHI *, Oumaima EL BAKHCHOUCH, Imad EL KATI, Nasser-Eddine AZZOUZI, \\ Hassan TABYAOUI
}

\author{
Natural Resources and Environment laboratory, Polydisciplinary Faculty of Taza, Sidi Mohamed Ben Abdellah \\ University, Fez, BP. 1223, Taza-Gare, Morocco. \\ fatima.elhammichi@usmba.ac.ma, hassan.tabyaoui@usmba.ac.ma
}

KEY WORDS: Cave, Inventory, Geodatabase, Atlas Mountain, Morocco

\begin{abstract}
:
This research aims to create and manage a database structure to record, analyze and produce spatial and attribute data on the caves of the Atlas Mountains in Morocco. The database model is developed as a Geodatabase for use in ArcGIS. Traditionally, cave scientists, or speleologists, have collected various data in multiple formats. In many cases, researchers collect the same data using different methodologies. This is undesirable, not only from the repetition of work, but perhaps more important because many more scientifically interesting caves are fragile environments that they cannot tolerate the collection of additional and especially redundant data. In addition, the geodatabase provides a common data format for sharing and sharing data between researchers.
\end{abstract}

\section{INTRODUCTION}

The karstic relief is a form of landscape that characterizes the geological formations of the northern Middle Atlas (Morocco). It results from the particular underground flows which are put in place progressively in the carbonate rocks (limestones and dolomies often of liassic age) and the saline rocks (gypsum and sometimes rock salt of the Triassic). The karst landscape is characterized by forms of surface corrosion but also by surprising deformations (sinkholes, stalagmites, stalactites, resurgences, lapiaz, avents, ruiniform landscapes ...). It is also an aquifer since groundwater is totally involved in its formation and operation.

Several studies show the importance of cave systems in the Moroccan Atlas mountains (Lamoroux \& Camus, 1981; Martin, 1981; Tennevin 1978, among others). This karst system is of interest to scientists, speleologists, hydrogeologists and tourists.

The majority of these caves, more scientifically interesting, are fragile environments that they cannot tolerate the collection of additional and especially redundant data. To help facilitate identification, data sharing, conservation and protection of these nonrenewable scientific and educational resources, it becomes important to identify and catalog this legacy in the form of fact sheets with illustrations, in the geospatial toolbox. Geographic information systems (GIS) have shown great promise in the management of data of various kinds. Geographical models and relationships that were previously unknown or forgotten can be discovered with simple mapping tools within GIS. More complex relationship analyzes and even prediction schemes can be performed with GIS modeling tools.

In this paper, we show the results of the development of a Geodatabase that allows recording, analyzing and producing spatial and attribute data on the caves of the Moroccan Atlas (Fig. 1).

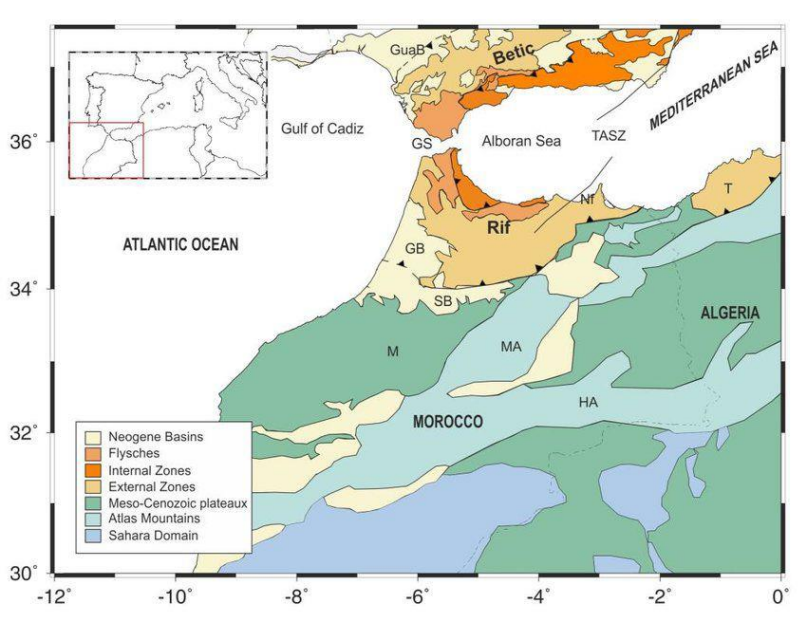

Fig. 1 - Simplified geological map of northern Morocco and southern Spain. The Atals Mountain is identified between the major domains. GB: Gharb Basin; GS: Gibraltar Strait; HA: High Atlas; M: Meseta; MA:Middle Atlas; SB: Saïss Basin.

\section{DESCRIPTION OF DATA SOURCES}

The great variation in the characteristics of the caves of the Atlas mountain in Morocco defined in the literature (see work of Lamoroux \& Camus, 1981; Martin, 1981; Tennevin 1978) provides a good test environment for an inventory of this karstic system. A first view allows creating structured digital forms taking into consideration the following information:

- General data on karst: identification reference, variety of surface forms (eg lapis, sinkholes, polje, dry valley, rock cones);

- Geographic location: Each karst landscape has coordinates on a reference system. Its cartographic representation in the GIS is usually made in the form of a point;

- Geological identification: geological setting of karstified formations; 
The International Archives of the Photogrammetry, Remote Sensing and Spatial Information Sciences, Volume XLII-4/W16, 2019 6th International Conference on Geomatics and Geospatial Technology (GGT 2019), 1-3 October 2019, Kuala Lumpur, Malaysia

- Morphological details: type, shape, depth, extent, layout...; Bibliographic identification: references of figuration (photography or drawing) and of quotation (thesis, article, unpublished documents);

- Descriptions: speleological, hydrogeological, geochemical $\ldots$

\section{DEVELOPMENT OF THE GEODATABASE}

The development of the Geodatabase on the caves follows the approach described by Arctur \& Zeiler (2004), and recommended by ESRI (Figs 2 and 3). The final schema of the Caves.mdb geodatabase contains 16 feature classes organized into 5 feature datasets, 5 raster datasets, and 3 object classes (Fig. 4). Relationship classes are developed to support feature classes.

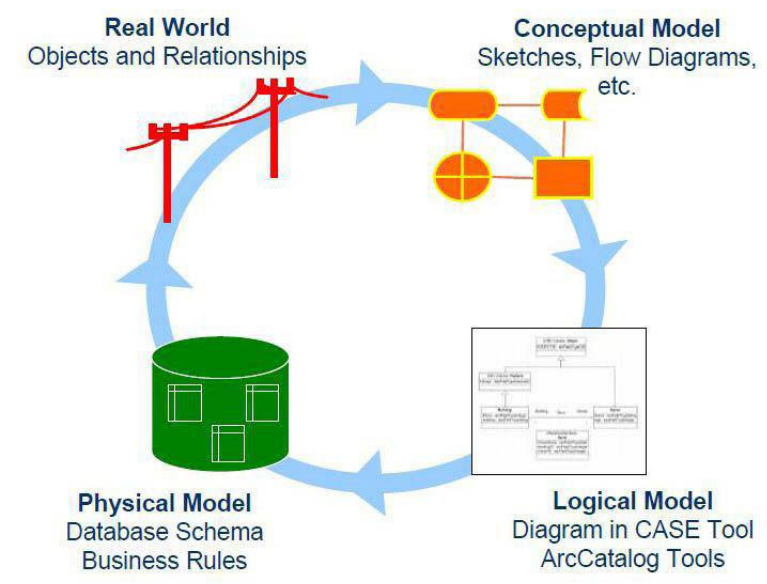

Fig. 2 - Principle of Geospatial Data Modeling

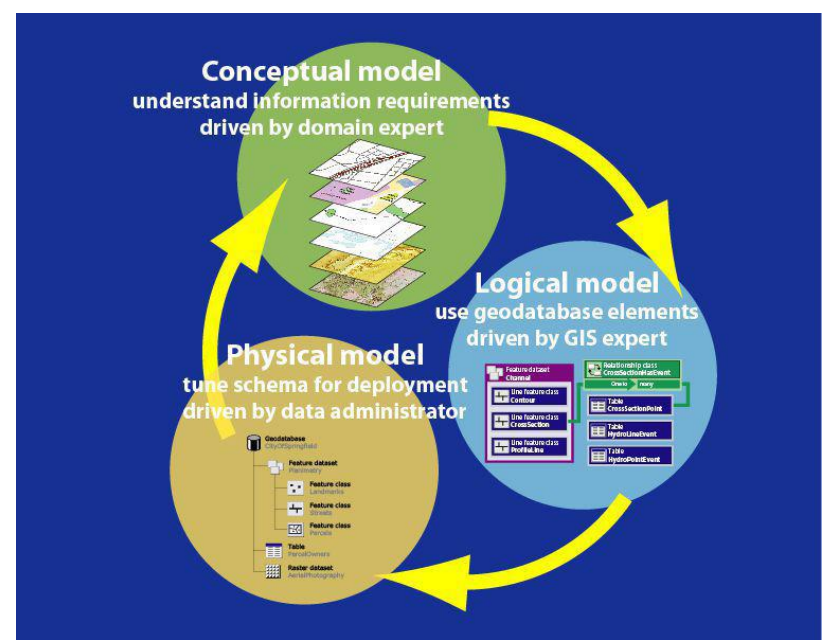

Fig. 3 - Conceptual modeling for the development of an ArcGIS geodatabase

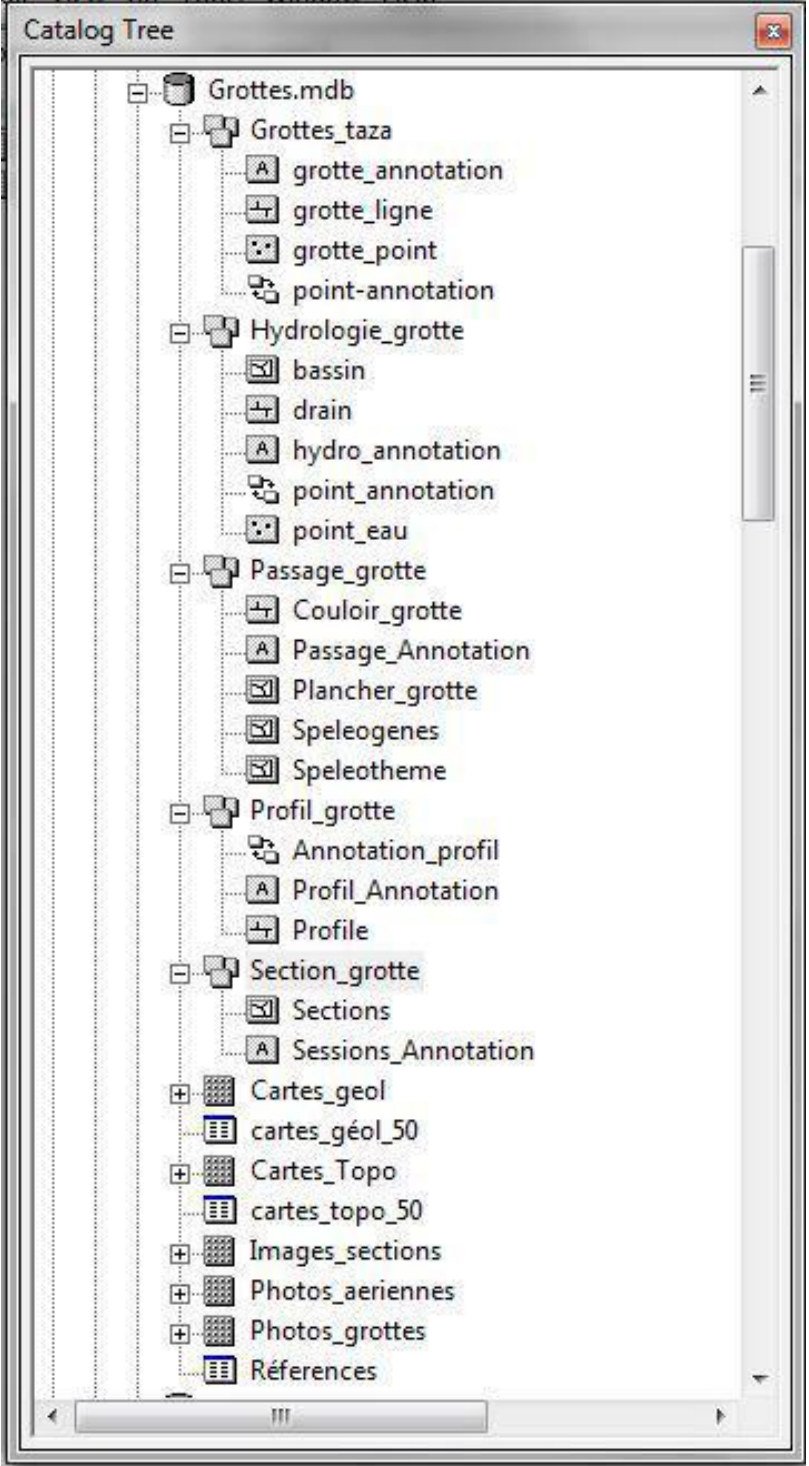

Fig. 4- ArcGIS (Esri ()) ArcCatalog view of the data model for the Moroccan Atlas Caves

The five feature datasets sets developed for this project corresponds to:

- Cave_data: Includes two main entity classes (cave-point and cave-line) and an Annotation feature class. The latter saves annotations and provides additional flexibility for symbology when creating maps;

Cave-section: includes data collected from profiles or cross-sections such as the height and width of the passage. Cave_profile: the profile is an important component in the description of a cave. It is often used to help visualize caves with labyrinthine extension or passage. The profile usually comes from diagrams drawn by explorers.

- Cave_Passage: This feature class set contains all the information for the plan view of the visitor passing through the cave. This is particularly useful when multiple researchers or organizations are working with a common set of data or a cave map. Feature classes refer to endings defined by speleologists. The feature classes includes five feature classes : Cave_Corridor, Speleogenic, Cave_Layer, Speleothem and Annotation ;

- Cave_hydrology : because water and its related hydrological systems are the main mechanism for cave 
The International Archives of the Photogrammetry, Remote Sensing and Spatial Information Sciences, Volume XLII-4/W16, 2019 6th International Conference on Geomatics and Geospatial Technology (GGT 2019), 1-3 October 2019, Kuala Lumpur, Malaysia

formation in the limestone rocks, and plays a major role in its ecosystems, hydrology is classified as a separate feature dataset : point_water (as a point), basin (as a polygon) represents depressions, lakes, or pools of water within of Cave and finally Drain (in line form) represents the underground drainage.

The Raster dataset includes image catalog classified in one of five themes: aerial photos, geological and topographic maps, section images and cave photos (for the satellite image catalog, field photos, amateur photos ...). These data are well suited to the structure of the raster dataset. They are most often referenced by a uniform and continuous code.

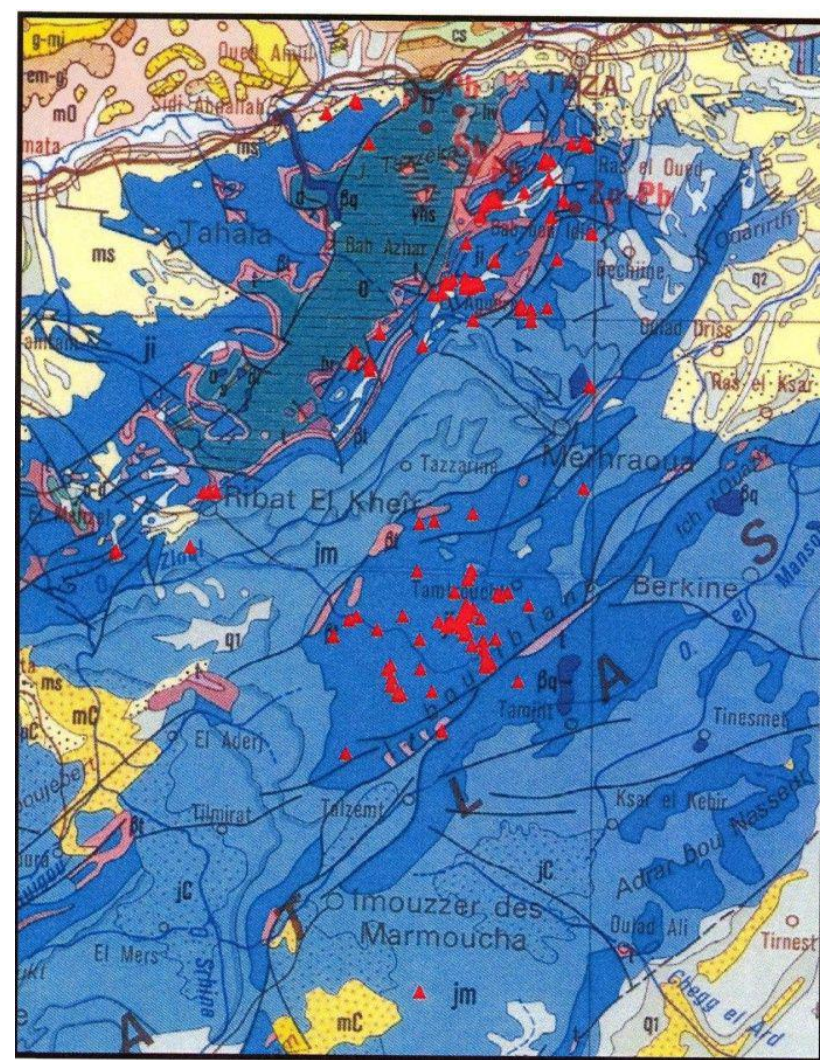

Fig. 5, 6 \& 7 respectively: Location of the cave (red dots) of the north of the Atlas mountain on the geological map of Morocco at 1/50000, the Landsat ETM+ satellite imagery and on a SRTM with $30 \mathrm{~m}$ spatial resolution
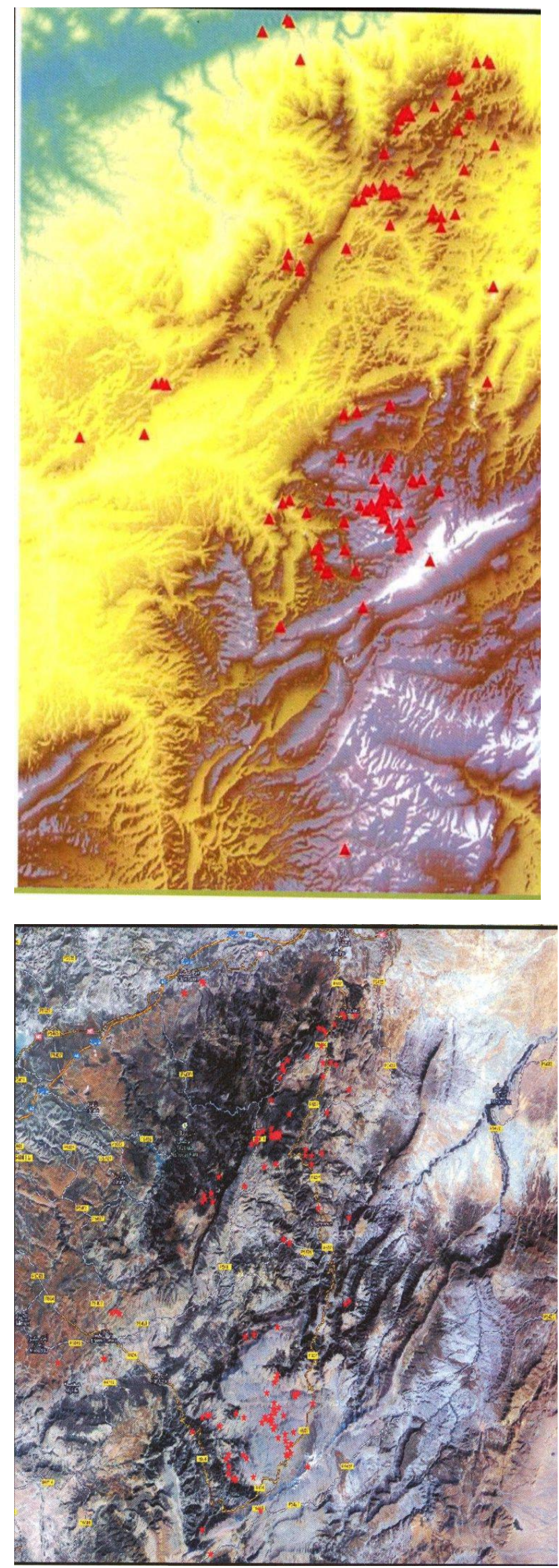


\section{RESULTS:}

The advanced graphical capabilities of the GIS allow maps to be developed for both caves and other elements related to the same location (Figs 5, $6 \& 7$ ). These maps can be used not only as a primary search tool, but also for interpretive and educational applications.

Researchers, students, specialists, and the amateur public can take virtual excursions and choose different components, using additional more detailed data such as digital geological maps, lithological data, stratigraphy, digital elevations models... These views can be digitally rotated and analyzed at an infinite number of angles.

This will help to publicize and promote the karst heritage of the mountain of the Moroccan Middle Atlas.

\section{CONCLUSION:}

An ArcGIS geodatabase data model of the Atlas Mountains cave in Morocco, was developed using standard ArcCatalog (Esri, ( )). The data model was then tested against an existing traditional cave map to determine whether or not the Geodatabase model was functional. The results were encouraging as the data model was able to handle most of the spatial and attribute types and their accompanying representation.

Some remarks remain and include the inability of the Geodatabase to facilitate several types of geometry for a single feature class and for the representation of definitive maps.

\section{REFERENCES}

Arctur, D. and Zeiler, M. (2004) - Designing Geodatabases: Case Studies in GIS Data Modeling, Redlands: ESRI. 393 p. 9.

Lamoroux, C. \& Camus, J. (1981) - Inventaire spéléologique du Maroc. Notes et mémoires, Sérv.Géol. Maroc. 233 p.

Martin J. (1981) - Le Moyen Atlas Central : étude géomorphologique. Notes et mémoires, Sérv. Géol. Maroc. Num. 258 bis. 445 p.

Société Spéléologique du Maroc (1953) - Cinq années d'explorations souterraines au Maroc. 51 p.

Tennevin M. (1978) - Paysages karstiques du Moyen Atlas septentrional. Revue Méditerranée, $\mathrm{N}^{\circ} 1$ et 2, pp. 23-32. 